Esta revista forma parte del acervo de la Biblioteca Jurídica Virtual del Instituto de Investigaciones Jurídicas de la UNAM

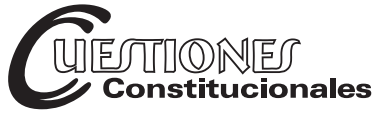

Revista Mexicana de Derecho Constitucional Núm. 44, Enero-Junio 2021

ISSN (versión electrónica): 2448-4881

\title{
El Ejecutivo siempre gana. División de poderes y fuerzas armadas en Argentina
}

The executive always wins. Separation of powers and armed forces in Argentina

Recepción: 11 de marzo de 2019

Aceptación: 25 de agosto de 2020

\section{Gerardo TRIPOLONE*}

RESUMEN: En el presente trabajo se analizan las relaciones y tensiones entre el Poder Ejecutivo y el Poder Legislativo en asuntos militares y de defensa nacional en Argentina. Inspirado en la investigación que Harlod Koh desarrolló en Estados Unidos, el objetivo es comprobar si, y en qué medida, el Ejecutivo prima sobre el Legislativo, tal como Koh lo hizo para el caso estadounidense. Mediante ejemplos históricos se aprecia que también es el caso en Argentina. No solo existe una primacía del presidente sobre el Congreso, sino que hay casos de abierta violación a la legislación sancionada por el segundo. Incluso pueden hallarse ejemplos de decisiones presidenciales tomadas en abierta contradicción de la Constitución. Finalmente, se buscan las razones constitucionales, históricas y políticas para que se dé esta primacía y se ofrecen ciertas pautas para pensar soluciones.
ABSTRACT: This work analyses the relations and tensions between the Executive and the Legislative branches on military affairs and national defense in Argentina. Inspired by the investigation that Harold Koh developed in the United States, the main is to prove if, and in which measure, the Executive has primacy over the Legislative, as Koh proved for the American's case. Through historical examples, it proved that this is also the case in Argentina. The President has not only a primacy over the Congress, but there are cases of open violation of the legislation passed by Congress. There are even cases of presidential decisions made in contradiction of the Constitution. Finally, it seeks the constitutional, historical and political reasons for this pattern and it offers some guides to think solutions.

* Investigador Asistente del Consejo Nacional de Investigaciones Científicas y Técnicas (CONICET, Argentina) y profesor de la Universidad Nacional de San Juan. Argentina. Correo electrónico: gerardo.tripolone@gmail.com ORCID 0000-0002-6969-9847 
Esta revista forma parte del acervo de la Biblioteca Jurídica Virtual del Instituto de Investigaciones Jurídicas de la UNAM

Palabras clave: Fuerzas armadas, división de poderes y Constitución argentina.
Keywords: Armed forces, separation of powers and constitution of Argentina.

\begin{abstract}
SUMARIO: I. Introducción. II. El "ciclo" de la Constitución de la seguridad nacional en Estados Unidos. III. La primacía constitucional y legal del Ejecutivo en Argentina. IV. El Congreso legisla y el Ejecutivo ignora. V. Las grandes victorias del Ejecutivo. VI. Las razones de las victorias. VII. Conclusión: de la impotencia a una propuesta realista. VIII. Fuentes consultadas.
\end{abstract}

\title{
I. INTRODUCCIÓN
}

Harold Koh (1990) estudió el funcionamiento de lo que llamó "ciclo de la Constitución de la Seguridad Nacional" en Estados Unidos. A partir de un caso paradigmático de uso del poder militar por parte del poder ejecutivo de aquel país en el escándalo "Irán-Contra", Koh (1990) describe un patrón: el presidente tiene la iniciativa en asuntos militares y de seguridad, el Legislativo consiente en estas políticas y el Judicial tolera las prácticas incluso reñidas con la legalidad o la propia Constitución.

El objetivo del presente trabajo es analizar si, y de qué manera, este patrón se ha dado en Argentina, en particular en las relaciones entre el Poder Ejecutivo (PE) y el Poder Legislativo (PL). Dejaremos para otro momento lo actuado por el Poder Judicial frente a las decisiones del Ejecutivo. Analizaremos los periodos de gobiernos constitucionales a partir de la restauración democrática en 1983, ya que buscamos apreciar si un Congreso en funciones ha sido capaz de poner límites a un Ejecutivo surgido del voto popular. La hipótesis es que, con las particularidades nacionales, el patrón descripto por Koh (1990) efectivamente se ha dado (y continúa dándose) en Argentina.

Hay buenas razones para defender que en asuntos relativos a la seguridad nacional (y también a la política exterior) los poderes ejecutivos de cualquier país primen sobre las asambleas legislativas en la formulación de políticas y orientación estratégica. Esto no lo discutiremos aquí. El punto por tratar es cómo la supremacía del presidente le ha permitido vulnerar los límites legislativos para el uso de las Fuerzas Armadas Argentinas 
Esta revista forma parte del acervo de la Biblioteca Jurídica Virtual del Instituto de Investigaciones Jurídicas de la UNAM

(FFAA). Incluso se ha dado casos en que el Ejecutivo ha podido ignorar expresamente lo establecido en la Constitución Nacional Argentina (CN) sobre poderes militares y aun así su accionar no fue impedido por el Congreso o incluso lo refrendó con posterioridad.

Debe quedar claro que no postulamos la existencia de un pasado en el cual el Ejecutivo estaba sometido a los márgenes de la legalidad y la $\mathrm{CN}$. La historia prueba una constante reafirmación de los poderes militares del presidente que logran imponerse sobre la voluntad del Congreso. Tampoco pensamos que el ejercicio de los poderes presidenciales en otras democracias en el mundo con sistemas constitucionales análogos al argentino sea limitado por los órganos legislativos, como si la ausencia de control fuese un déficit original en nuestra cultura política. Argentina no es una anomalía en este sentido. En estas páginas haremos comparaciones con lo que sucede en Estados Unidos, ya que el orden constitucional (en general y sobre aspectos militares en particular) es muy similar al argentino y suele constituir un modelo para el análisis de nuestro derecho constitucional.

Lo más importante de un estudio de estas características es, por un lado, apreciar cómo en concreto se ejercen los poderes militares en Argentina. Buscamos aclarar, al menos introductoriamente, la praxis constitucional del reparto de competencias en asuntos militares entre el PE y el PL. Por el otro, porque permite tener una idea más certera de cómo se articula, en general, el control sobre el poder. Sea esto indeseable o no, la ley parece impotente para frenar el ejercicio del poder (en general, pero en especial el militar) tanto en situaciones de emergencia (reales o pretendidas) como en tiempos de normalidad.

\section{EL “CICLO” DE LA CONSTITUCIÓN DE LA SEGURIDAD NACIONAL EN ESTADOS UNIDOS}

Harold Koh (1990: 5, 12-13 y 62-63) sostiene que escándalo Irán-Contra no debe ser tomado meramente como un ilícito del entonces presidente Ronald Reagan y otros funcionarios públicos. Para el autor, el punto crucial es lo que enseña sobre el patrón que guía las relaciones entre los tres poderes del Estado en asuntos de seguridad nacional.

Para Koh (1990), el Ejecutivo norteamericano, al menos desde la década de 1970, siempre se impone frente a los otros poderes porque (i) tiene iniciativa plena en asuntos de seguridad, defensa y política militar; (ii) 
Esta revista forma parte del acervo de la Biblioteca Jurídica Virtual del Instituto de Investigaciones Jurídicas de la UNAM

el Congreso consciente lo que hace el PE y (iii) el Poder Judicial tolera sus decisiones (Koh, 1990: 5). El autor elabora este ciclo para analizar las razones institucionales que posibilitó el apoyo militar secreto de su país a los Contra en Nicaragua financiado mediante la venta igualmente secreta de armas a Irán durante la guerra con Irak.

Este patrón se halla en casos de intervenciones a gran escala - como en Vietnam luego del episodio en el Golfo de Tonkín que empujó la decisión de intervenir de Lyndon Johnson - o de menor intensidad y tiempo - como el intento de rescatar los civiles secuestrados en la embajada en Irán decidida por James Carter o la intervención militar en Granada por Ronald Reagan, entre otros casos (Koh, 1990: 38-39)—. La tendencia se ha acentuado desde entonces.

La presidencia de George W. Bush y la war on terror ofrecen los ejemplos más actuales. Harold Koh era decano en la Universidad de Yale durante los gobiernos de Bush y es reconocido por su crítica a esta situación de preeminencia del ejecutivo, tanto en la obra citada como en trabajos y declaraciones posteriores. Sin embargo, hay autores que afirman lo mismo, solo que para defenderla. Por ejemplo, John Yoo (2009: 410) sostiene que la forma en que Bush pudo continuar la guerra de Irak durante la "surge" de 2007 a pesar de la oposición de parte de los miembros del Congreso sirve como "recordatorio tanto de la preeminencia constitucional del presidente en la guerra, como de la reluctancia del Congreso de usar sus poderes para frenarlo".

Posner y Vermeule argumentan algo similar para toda situación de emergencia: el poder ejecutivo actúa, el legislativo acepta y las cortes son deferentes (Posner y Vermeule, 2007: 1). Sólo cuando la situación de emergencia aminora, los jueces comienzan a oponerse a las acciones del ejecutivo alegando que se excedió en sus facultades o violó garantías constitucionales. Únicamente en ese momento el Congreso aprueba una nueva legislación para constreñir al ejecutivo en un futuro y evitar nuevos

1 La surge (oleada) fue una decisión que tomó Bush para afrontar la guerra civil desatada, sobre todo, a partir de 2006 en Irak. Para llevarla adelante, Bush descabezó el Pentágono (su secretario de defensa Donald Rumsfeld tuvo que irse) y el Centcom (Comando Central) con sus generales a cargo de la campaña. También ignoró las recomendaciones del Iraq Study Group, una comisión creada por el Congreso de Estados Unidos para asesorar al presidente, y, en general, la opinión pública desfavorable al envío de más tropas (Bergen, 2011: 273-296; Smith, 2016: 524-548).

Cuestiones Constitucionales, Núm. 44, Enero-Junio 2021

ISSN: $2448-4881$ 
Esta revista forma parte del acervo de la Biblioteca Jurídica Virtual del Instituto de Investigaciones Jurídicas de la UNAM

desbordes. Sin embargo, ante una nueva emergencia el ciclo se reanuda con acciones del presidente que son consentidas por los otros poderes.

Esta primacía del ejecutivo se debe a muchas razones. Una de ellas es a la naturaleza y las necesidades del instrumento militar, sobre todo en situaciones de guerra o emergencia. Como sostiene Baker (2007: 25), el Ejecutivo es un poder unitario que, a diferencia del Congreso, tiene las ventajas de la "sorpresa, velocidad y secreto". Esto es vital para el comando operacional de las fuerzas armadas, que difícilmente podría funcionar si estuviese sujeto al control de diversas agencias o de otros poderes del Estado. Además, continúa el autor, la decisión unilateral del ejecutivo evita "la obstrucción de la política de partidos" (Baker, 2007: 26).

Aunque el propio Baker (2007: 26-27) señala contraargumentos y beneficios del control de las acciones militares del ejecutivo por parte del Congreso y, en general, de la opinión pública, la primacía del presidente es incuestionable. Esto parece promover la deferencia de los otros poderes incluso en casos en que el presidente ha ignorado, interpretado de forma sumamente flexible o directamente violado normas dictadas por el legislativo o decisiones del Poder Judicial.

Como dijimos, la guerra contra el terrorismo iniciada en 2001 ha sido (y sigue siendo) pródiga en ejemplos sobre el punto. Incluso en temas relativos a los derechos humanos más fundamentales, el ejecutivo ha triunfado frente a la legislación. Así fue, por caso, con la prohibición de tortura que dictó el Congreso de Estados Unidos en 2005. A iniciativa del senador republicano John McCain, el legislativo buscó frenar los "enhanced interrogation techniques", eufemismo para designar la legitimación de la tortura realizada por la Agencia Central de Inteligencia (CIA) y las fuerzas armadas estadounidense con los detenidos sospechados de terrorismo. El gobierno de George W. Bush luchó para que la ley no se aprobara. Sin embargo, al sancionarse por el Congreso, Bush no la vetó. Lo que hizo fue dictar una reserva de interpretación que afirmaba que el presidente "se reserva la interpretación de esa ley en la órbita de su actuación" (Smith, 2016: 470 y 471). El argumento de Bush y sus asesores se basaba en la cláusula de comandante en jefe por la cual las operaciones militares se subordinaban al presidente. Al ser esta facultad otorgada por la Constitución norteamericana al ejecutivo de forma directa, el legislativo invadía una potestad que no le correspondía. Nada pudo hacer el Congreso frente a esta interpretación. 
Esta revista forma parte del acervo de la Biblioteca Jurídica Virtual del Instituto de Investigaciones Jurídicas de la UNAM

Lo mismo sucedió con la reserva interpretativa en el contexto de la renovación del Patriot Act. Bush volvió a advertir que se reservaba la interpretación de la nueva legislación en todo lo que constriña su poder. Tenía en cuenta en especial las restricciones que buscaron imponerse sobre la obtención de información por parte del Oficina de Investigación Federal (FBI). Según Smith (2016: 474), estos ejemplos son solo "la punta del iceberg" del poder presidencial durante la war on terror. Alegando ser él el comandante en jefe (algo cierto), Bush se sobrepuso a las cuatro veces que el Congreso intentó prohibir que tropas estadounidenses entren en combate en Colombia. Para el presidente, estas normativas del Congreso tenían "naturaleza consultiva" ya que la potestad sobre el uso de las fuerzas armadas recae en el ejecutivo.

En dos oportunidades, el Congreso buscó frenar la obtención de información sin orden judicial por los servicios de inteligencia que se hallan bajo el mando del presidente. En ambos casos, Bush firmó una declaración diciendo que el único comandante en jefe es el presidente y es él quien decide cómo se colecta la información en situación de guerra. Ocurrió lo mismo cuando el Congreso dictó una ley por la que el Ejecutivo debía informar sobre los black sites de la CIA, i.e. los sitios fuera del territorio de Estados Unidos en los que la central de inteligencia encerraba secretamente (y sometía a interrogatorio a veces mediante tortura) sospechados de terrorismo. De nuevo, Bush argumentó que como comandante en jefe no estaba obligado a dar esos informes.

Es cierto que la Corte Suprema de Estados Unidos le propinó un golpe muy duro a la administración Bush en la causa Hamdan v. Rumsfeld en junio de 2006. El tribunal, contra la pretensión del Ejecutivo, declaró inconstitucionales las comisiones militares para juzgar a civiles; determinó que el hábeas corpus y demás garantías constitucionales se aplicaba a los prisioneros de Guantánamo y, en general, a quienes estuviesen bajo el poder de las fuerzas armadas de Estados Unidos sin importar si estaban dentro o fuera del territorio del país; y estableció, contra lo que había declarado Bush, que la Convención de Ginebra sí se aplicaba en el combate contra Al Qaeda.

Para los defensores de Bush, la decisión fue tomada como una intromisión del poder judicial en potestades del ejecutivo (Yoo, 2006: 235-238). En el interior de su gabinete se debatió fuertemente qué hacer frente a este fallo. Su vicepresidente, Dick Cheney, y el procurador general, Alber- 
Esta revista forma parte del acervo de la Biblioteca Jurídica Virtual del Instituto de Investigaciones Jurídicas de la UNAM

to Gonzales, se opusieron y aconsejaron al presidente que no cumpliera con las obligaciones impuestas por la Corte. La por entonces secretaria de Estado, Condoleeza Rice, al contrario, instó a Bush a que se atenga a lo dicho por el tribunal para evitar dejar como legado de su presidencia una mancha tan oscura (Smith, 2016: 503-504). Bush optó por este camino, ${ }^{2}$ pero envió un proyecto de ley al Congreso para legitimar las comisiones militares. Otra vez la Corte lo declaró inconstitucional el 12 de junio de 2008 en la causa Boumediene v. Bush.

Estos dos fallos parecerían mostrar el control que el poder judicial ejerce sobre los actos del presidente y del Congreso. Sin embargo, si se analizan en el contexto se ve que ambas causas (y, en especial, la segunda) se fallaron en momentos de desprestigio del presidente. Desde el inicio de la war on terror se judicializaron las pretensiones del Ejecutivo de ampliar su poder. Pero los tribunales fueron deferentes. La Corte consintió la designación de enemigos combatientes a ciudadanos americanos en Padilla y en Hamdi, ambos de 2004, más allá de sostener que el acusado podía controvertir esta decisión. Solo cuando el desprestigio que se produjo, sobre todo, por el fiasco de la guerra en Irak y cuando Bush estaba llegando al final de su segundo mandato, es que la Corte dictó ambos fallos contrarios a sus pretensiones. Por lo demás, el Ejecutivo logró evitar las consecuencias de éstos hasta el final. Nunca dejó de detener prisioneros y de interferir comunicaciones telefónicas sin orden judicial. Tampoco cerró Guantánamo ni prohibió las rendiciones (i.e. el secuestro de una persona en el extranjero y la abducción hacia un país donde la tortura es práctica habitual para ser interrogado), ni cumplió los Convenios de Ginebra. Durante la guerra contra el terrorismo, el ejecutivo estadounidense definitivamente ganó.

\section{LA PRIMACÍA CONSTITUCIONAL Y LEGAL DEL EJECUTIVO EN ARGENTINA}

En Argentina, el poder militar es exclusivamente potestad del Estado federal. Las provincias no pueden "armar buques de guerra o levantar ejércitos, salvo el caso de invasión exterior o de un peligro tan inminente

2 Es interesante notar que, según el relato de Smith (2016) citado, Bush se convence por el argumento estrictamente político de Rice y no por razones jurídicas. Esto es algo que debe recordarse para entender cómo funciona la distribución de competencias en asuntos de seguridad, al menos en Estados Unidos. 
Esta revista forma parte del acervo de la Biblioteca Jurídica Virtual del Instituto de Investigaciones Jurídicas de la UNAM

que no admita dilación dando luego cuenta al Gobierno federal" (art. 126, $\mathrm{CN}$ ). Tampoco pueden "declarar, ni hacer la guerra a otra provincia" (art. 127, CN). Como veremos más adelante, las milicias provinciales (creadas a imagen de la Guardia Nacional de Estados Unidos) se hallaban en la $\mathrm{CN}$ original de 1853 , pero ya sobre el final del siglo XIX no funcionaba ninguna y la cláusula que las legitimaba fue eliminada en la reforma constitucional de 1994. Por tanto, cuando hablamos de FFAA nos referimos exclusivamente al Ejército Nacional, la Armada Argentina y la Fuerza Aérea Argentina, las tres ramas de las FFAA que dependen del Estado Nacional.

Según la ley de defensa nacional 23554 de 1988, la Gendarmería Nacional y la Prefectura Naval Argentina forman parte del sistema de defensa nacional. Estas dos instituciones de seguridad militarizadas surgieron en el seno del Ejército y la Marina, respectivamente. Sin embargo, según la ley de seguridad interior 24059 de 1991 forman parte también del sistema de seguridad. Además, tanto la Gendarmería como Prefectura pasó de depender del Ministerio de Defensa al Ministerio del Interior primero y luego de Seguridad. Con lo cual, más allá de funciones de complementación con las FFAA, constituyen fuerzas de seguridad dedicadas a la seguridad interior.

\section{La declaración de guerra}

Las facultades del Congreso de la Nación al respecto se hallan en el artículo 75, incisos 25 a 28 de la CN. Estas cláusulas incluyen nada menos que la declaración de guerra y la orden de represalias. Se sigue aquí la idea republicana sobre quién debe decidir la guerra: el pueblo mismo o sus representantes quienes, en definitiva, irán a luchar y probablemente morir (Kant, 2010: 311-312).

Sin embargo, el artículo 99.15 establece que el PE "declara la guerra y ordena represalias con autorización y aprobación del Congreso". Una directiva de interpretación lingüística de textos jurídicos indica que a dos términos distintos deben darse significados diversos salvo razones de peso en contra. En este sentido, "autorización" y "aprobación" debe entenderse como dos conceptos diferentes. Y de hecho lo son. Mientras autorización implica un acto previo a algo, aprobación supone un momento posterior. 
Esta revista forma parte del acervo de la Biblioteca Jurídica Virtual del Instituto de Investigaciones Jurídicas de la UNAM

Teniendo esto en cuenta, ¿cómo es el procedimiento para declarar la guerra en Argentina? ¿Qué órgano actúa primero, el PL que autoriza al PE a declarar la guerra o el PE que la declara y luego recibe la aprobación del Congreso, o ambas?

Teniendo en cuenta el artículo 99.15, podría entenderse que la autorización (previa) del Congreso es para declarar la guerra y la aprobación (posterior) es para las represalias. Sin embargo, no es aceptable, ya que al establecer las facultades del Congreso habla de "autorizar al Poder Ejecutivo a declarar la guerra" (75.25) y "facultar al Poder Ejecutivo para ordenar represalias" (75.26). Tanto "autorizar" como "facultar" indican un paso previo a la declaración de guerra o la orden de represalias.

Lo problemático es que ninguno de los dos incisos del 75 habla de "aprobación" de una declaración de guerra o represalia hecha por el PE. Esto podría entenderse como una limitación al PE: solo puede declarar la guerra $\mathrm{u}$ ordenar represalias mediando una previa autorización del Congreso. Si esto es así, entonces las dos palabras utilizadas en el 99.15 significarían lo mismo o, lo que es igual, el término "aprobación" estaría vaciado de contenido. La consecuencia sería problemática: quien ejerce la presidencia no podría declararse la guerra durante el periodo de receso del Congreso (desde el 30 de noviembre hasta el 1o. de marzo) sin convocar a sesiones extraordinarias. Así lo entiende, por ejemplo, Ekmekdjian (1997: 659).

La segunda posibilidad es que la "aprobación" del Congreso sea necesaria durante su receso luego de una declaración del PE en esos meses, siendo la autorización requisito durante el periodo de sesiones ordinarias. Sin embargo, cuando los constituyentes quisieron establecer que ciertas facultades del Congreso son ejercidas por el PE durante el receso de aquél con su aprobación posterior, como sucede con el estado de sitio (artículos 75.29 y $99.16 \mathrm{CN}$ ) y la intervención federal (artículos 75.31 y $99.20 \mathrm{CN}$ ), lo hicieron expresamente. No fue así con la declaración de guerra.

Ekmekdjian estaría en lo cierto, más allá de que la consecuencia que extrae (que el PE no puede declarar la guerra sin convocar previamente al Congreso) puede no ser acertada. Puede dudarse del acierto de Ekmekdjian porque existe una última alternativa: entender que el PE puede declarar por sí la guerra durante el receso sin necesidad de aprobación posterior del Congreso, ya que la $\mathrm{CN}$ nada dice al respecto. El problema aquí es que el término "aprobación" se vaciaría de contenido, de la misma forma que lo hace Ekmekdjian solo que, en este caso, para inclinar la balanza en favor del PE. 
Esta revista forma parte del acervo de la Biblioteca Jurídica Virtual del Instituto de Investigaciones Jurídicas de la UNAM

Por último, también podría entenderse que el PE puede, durante el receso o el periodo de sesiones ordinarias, declarar la guerra con la autorización previa y también con aprobación posterior. Esta interpretación, sumamente difícil de sostener en la práctica, no ha sido propiciada por ningún gobierno de iure ni la hemos hallado en la doctrina constitucional. Por lo demás, insistimos, el artículo 75 no dice "aprobar" una declaración de guerra declarada por el PE.

Este problema normativo no ha preocupado a la doctrina constitucional. Mucho menos en la actualidad, algo que es entendible. Argentina solo ha declarado la guerra en dos oportunidades, contra Paraguay en 1865 y contra las potencias del Eje a semanas de concluir la Segunda Guerra Mundial en 1945. En la segunda oportunidad, el Congreso no estaba en funciones desde 1943.

La práctica mundial es la de no declarar la guerra (Fernández Rodríguez y Sansó-Rupert, 2010: 740). Estados Unidos, que tiene disposiciones similares a las nuestras en su Constitución, no lo ha hecho desde la Segunda Guerra Mundial (Starr-Deele, 2014: 23), más allá de las intervenciones militares casi constantes en todo el mundo que ha realizado desde entonces. Para salvar esto se ha distinguido, de forma algo barroca, entre "declarar la guerra", facultad del Congreso, y "hacer la guerra", facultad del ejecutivo (Baker, 2007: 34).

El derecho internacional ha proscripto la guerra, por lo que toda acción armada es entendida como una acción policial tendiente a acabar con los criminales que atentan contra la paz mundial y no como un conflicto entre Estados para resolver alguna controversia ${ }^{3}$. Ya no se pelean más guerras y ningún Estado declara formalmente que está en una, por lo que las discusiones sobre esta potestad en el interior de los sistemas constitucionales han perdido parte de su vigencia.

Ahora bien, esta mutación en la guerra (de conflicto inter-estatal a acción policial) ha beneficiado al ejecutivo y la concentración de poder en sus manos. Los presidentes de Estados Unidos han podido llevar a su país a la guerra en Corea, Vietnam, Irak, Afganistán y de nuevo Irak (por no contar los usos de la fuerza "menores" a lo largo de la segunda mitad del siglo XX y estas dos primeras décadas del XXI) sin necesidad de decla-

3 De esto se dio cuenta prontamente Schmitt (2005) e hizo críticas profundas a lo largo de su obra (p. 5). Max Boot (2003, 19 de febrero), en el siglo XXI, defiende la idea de que Estados Unidos está llamado a ser la policía internacional.

Cuestiones Constitucionales, Núm. 44, Enero-Junio 2021

ISSN: $2448-4881$ 
Esta revista forma parte del acervo de la Biblioteca Jurídica Virtual del Instituto de Investigaciones Jurídicas de la UNAM

ración de guerra, más allá de las "autorizaciones para el uso de la fuerza" emitidas por el Congreso a partir de la década de 1970 y solo en algunos casos. En todos, la decisión de atacar ha sido siempre del ejecutivo y el Congreso ha acompañado con posterioridad. Con las tropas combatiendo y la apelación a una emergencia, la historia constitucional norteamericana muestra que el Congreso es renuente a frenar una incursión militar ${ }^{4}$.

\section{El comandante en jefe dispone y decide en la excepción}

Otro camino por el que el PE triunfa sobre el PL surge del debate sobre la distribución de competencias militares, en particular en lo que respecta a la facultad de disposición de las FFAA (artículo 99.14 CN) y la cláusula de comandante en jefe (artículo 99.12 CN). El alcance de los poderes que tiene el comandante en jefe no es claro, por lo que sirve como base para ampliar las facultades presidenciales en este aspecto. De hecho, según afirma Huntington (2002), la función más importante que esta cláusula ha tenido en Estados Unidos ha sido la de expandir los poderes presidenciales ( $\mathrm{p}$. 184), algo que también puede servir de argumento en nuestro país. Además, la facultad de disposición de las FFAA está otorgada al presidente por la propia CN y es ejercida "según las necesidades de la Nación”, por lo que resulta una facultad en apariencia discrecional.

Con base en estas cláusulas, como hemos analizado en otro trabajo (Tripolone, 2018a), constitucionalistas como Bidart Campos (1999, t. III: 307), Sinópoli (2003: 70) y Palazzo (2010: 834) consideran que la legislación no puede limitar el poder de disposición de las FFAA incluso en asuntos en que el Congreso le ha vedado actuar mediante la legislación. Ciertos constitucionalistas siguen una doctrina similar en Estados Unidos y fue la base para los memorándums que la Oficina de Asuntos Legales del ministerio de Justicia emitió durante la Presidencia de Clinton y, con mayores consecuencias, con los que fundaron la expansión de los poderes

4 Como afirma Starr-Deelen (2014: 42), "Normalmente, el Congreso falla en el control del poder que reclama el presidente [en cuestiones de seguridad nacional], o bien porque es controlado por el mismo partido político que el Ejecutivo, o bien porque sus integrantes calculan que hay más para perder que para ganar en desafiar las acciones del presidente en nombre de la seguridad nacional". 
Esta revista forma parte del acervo de la Biblioteca Jurídica Virtual del Instituto de Investigaciones Jurídicas de la UNAM

presidenciales luego de los atentados el 11 de septiembre de 2001 (Smith, 2016: 257-258). ${ }^{5}$

Por su parte, las facultades de emergencia del presidente en Argentina no tienen correlato en la Constitución de Estados Unidos. La más importante es, sin dudas, la posibilidad que tiene de declarar el estado de sitio por sí mismo cuando el Congreso se halla en receso. Aunque el PL deba ratificar esta declaración, la celeridad del PE le permite actuar entre la declaración y la ratificación, restringiendo derechos, ordenando arrestos y traslados que pueden ocasionar perjuicios graves.

La declaración del estado de sitio activa la posibilidad de utilizar a las FFAA en asuntos de seguridad interna, tal cual lo legisla el título VI de la Ley 24.059 de seguridad interior. El artículo 31 establece que, una vez declarado el estado de sitio, si las fuerzas de seguridad "a criterio del presidente de la Nación" son insuficientes, puede valerse de las FFAA para "el restablecimiento de la seguridad interior dentro del territorio nacional". Como recaudo previo, el artículo 32 exige que para este empleo de las FFAA se declare el estado de sitio, facultad del Congreso de la Nación pero que, como vemos, puede ejercer el PE durante el receso de aquél.

La cláusula de comandante en jefe y la facultad de disponer de las FFAA que otorga la $\mathrm{CN}$ ofrecen dos marcos de discusiones que pueden justificar la utilización por parte del PE del poder militar incluso más allá de los límites de la legislación. Al contrario, la facultad de valerse de ellas en caso de estado de sitio está reconocida expresamente en la ley de seguridad interior. En cualquier caso, todas ellas demuestran por qué el sistema constitucional y legal está diseñado para que el PE gane.

\section{EL CONGRESO LEGISLA Y EL EJECUTIVO IGNORA}

Luego de la restauración de la democracia en 1983, el presidente Raúl Alfonsín promovió fuertes cambios en el control civil de las FFAA para que dejaran de ser un factor de poder que condicionara las autoridades democráticas, como lo habían sido desde 1930. En este sentido, Alfonsín eliminó la figura de comandante en jefe en cada una de las tres fuerzas que existían con anterioridad para asumir él mismo la función (tal como manda la $\mathrm{CN}$ ); promovió por un decreto el juzgamiento de los delitos co-

5 En contra de estas posiciones en Argentina, Quiroga Lavié et al. (2009, t. II: 958).

Cuestiones Constitucionales, Núm. 44, Enero-Junio 2021

ISSN: $2448-4881$ 
Esta revista forma parte del acervo de la Biblioteca Jurídica Virtual del Instituto de Investigaciones Jurídicas de la UNAM

metidos durante la última dictadura militar; redujo drásticamente el presupuesto a las FFAA, entre otras acciones.

Por su parte, el Congreso Nacional dio quizás los pasos más significativos desde el punto de vista institucional y de política a largo plazo. La sanción de la ley de defensa nacional 23554, con apoyo multipartidario en 1988, fue el hito fundamental (DerGhogasian, 2010: 13; Diamint, 2014: 100; Ugarte, 2013: 61). Junto a las leyes de seguridad interior (1992) y de inteligencia (2001), constituyó el pilar en el que se asentó el control civil de las FFAA. La razón principal radica en la distinción tajante entre asuntos de seguridad interior y de defensa nacional que todavía rige (artículo 4). Las FFAA se encargan solo de los segundos, los cuales se relacionan con el enfrentamiento de "agresiones de origen externo" (artículo 2).

Este cimiento legal no fue acompañado por decisiones del PE que consolidaran el gobierno civil de las FFAA. A diferencia del Congreso, el PE mantuvo una relación que los especialistas han llamado "delegativa" sobre las instituciones militares (Montenegro, 2013: 196-199). Eran éstas, y no quien ejercía la presidencia y el Ministerio de Defensa, quienes diseñaban los planes operacionales y estratégicos, proponían ascensos y designaciones del personal, distribuían el presupuesto, organizaban territorialmente las dependencias, entre otras tareas centrales. El Ministerio de Defensa, quizás el más débil y relegado del gabinete, cumplía en estos temas un papel formal y el PE refrendaba lo decido por quienes son sus subordinados de uniforme.

Para el caso particular del Ejército, Lafferriere y Soprano (2015) afirman que existe una diferencia sustancial entre la legislación que organiza la fuerza con lo que realmente sucede en el terreno. Para los autores, la falla principal se encuentra en la relación entre el presidente y las FFAA. No faltan leyes ni están desactualizadas. El problema son las directivas que solo el comandante en jefe, el presidente, puede dar y que, o bien no se dan, o bien no son puestas en práctica (Lafferriere y Soprano, 2015: 133-140).

La relación delegativa se extendió hasta el 2005, al menos según los análisis de Montenegro (2013) y Lafferriere y Soprano (2015: 100, n. 29). El problema del control civil de las FFAA y el planeamiento desde el Ministerio hacia las instituciones castrenses - y no desde las FFAA que hacían refrendar sus planes a las autoridades civiles - se habría logrado. De esta manera, el control civil establecido en la $\mathrm{CN}$ tendría un principio de 
Esta revista forma parte del acervo de la Biblioteca Jurídica Virtual del Instituto de Investigaciones Jurídicas de la UNAM

cumplimiento. El presidente habría establecido su supremacía sobre las FFAA. Sin embargo, el Congreso ha sido impotente frente a las victorias del PE sobre su legislación.

\section{LAS GRANDES VICTORIAS DEL EJECUTIVO}

El PE ha ganado siempre en materia militar frente al Congreso de la Nación. En estas páginas analizaremos solo lo sucedido a partir de la presidencia de Raúl Alfonsín y hasta fin de la presidencia de Mauricio Macri, esto es, desde 1983 hasta 2019.

\section{Raúl Alfonsín}

Pocos meses después de sancionada la Ley 23554, el 23 de enero de 1989, un grupo guerrillero liderado por Enrique Gorriarán Merlo, llamado Movimiento Todos por la Patria (MTP), intentó tomar el cuartel del Regimiento de Infantería Mecanizado 3 (RI3) localizado en La Tablada. Aunque resultó infructuoso, se desarrollaron fuertes enfrentamientos entre los efectivos del Ejército (muchos de ellos conscriptos), la policía y el grupo guerrillero.

El presidente Raúl Alfonsín ordenó a las FFAA actuar. Se movilizaron de otras dependencias más de 3,000 efectivos con tanques y artillería para enfrentar a medio centenar de guerrilleros. Como argumentó el Estado argentino ante la Comisión Interamericana de Derechos Humanos, esta potestad le asistía al presidente por ser el "comandante en jefe de las Fuerzas Armadas" y no necesitaba orden judicial. De hecho, la posibilidad de ordenar que las FFAA se movilicen está, se dijo, "sustraída" del Poder Judicial. Para el Estado, estas facultades son discrecionales del PE (Comisión Interamericana de Derechos Humanos, 1997, párrafos 71 y 73).

Bajo la tesis de la imposibilidad de restricción de la facultad de disposición de las FFAA por parte del Congreso que vimos más arriba, esta idea es acertada. Porque es claro que la decisión de Alfonsín vulneró la legislación promulgada por él mismo pocas semanas antes que limitaba el uso de las FFAA a agresiones de origen externo. El MTP era un grupo armado surgido en el país y que actuaba dentro del límite de las fronteras. Es evidente que los integrantes del RI3 tenían el derecho de defenderse del ataque. Lo 
Esta revista forma parte del acervo de la Biblioteca Jurídica Virtual del Instituto de Investigaciones Jurídicas de la UNAM

que no es para nada evidente es que pueda ordenarse a otras guarniciones de las FFAA a trasladarse hasta el lugar para repeler la agresión, teniendo a disposición las fuerzas de seguridad que ya habían rodeado la zona y estaban actuando.

El combate se alargó por treinta horas. Treinta y tres guerrilleros, catorce militares y cuatro policías murieron. Cuatro guerrilleros que habían sido fotografiados vivos durante la rendición, fueron fusilados o desaparecidos (Larraquy, 2017: 708). La Comisión Interamericana de Derechos Humanos dictaminó que el Estado argentino debía investigar los supuestos delitos cometidos por las FFAA durante el enfrentamiento. En el contexto de una utilización de las FFAA por fuera de lo que la ley de defensa nacional prescribía, se sospecha que volvieron a ocurrir delitos graves como torturas, apremios ilegales y desapariciones.

El 16 de marzo de ese año (menos de dos meses después del atentado en La Tablada), el presidente Alfonsín dictó el decreto 327/89 que profundizó la abrogación de la ley del Congreso por parte del PE, ahora mediante un documento legal. En los fundamentos, el presidente argumentó que "dadas las particularidades de la acción terrorista subversiva", la "Nación en su conjunto" resultaba agredida. Por tanto, continúa, "se deben instrumentar medidas de defensa que se irán graduando según la magnitud de la agresión, para lo cual se recurrirá a las Fuerzas Policiales o de Seguridad, dentro de sus respectivas jurisdicciones, pudiendo finalmente llegarse al empleo de las Fuerzas Armadas". El presidente, según el decreto, está facultado para poner en cabeza de las FFAA la "zona de operaciones" en los que surja el conflicto y subordinar a ellas las policías provinciales y federales, tal como sucedió durante el Plan Conintes. Contrariamente a lo establecido por la ley, el presidente estaba involucrando a las FFAA en asuntos internos si lo consideraba necesario.

Por otra parte, el decreto apuntaba a la supuesta necesidad de adoptar disposiciones que permitieran flexibilizar el empleo de los organismos del Sistema Nacional de Inteligencia. La ley de defensa nacional sancionada en 1988 prohibió realizar tareas de inteligencia militar que tuvieran como hipótesis cuestiones de política interna (artículo 15 ley 23554). Sin embargo, el presidente Alfonsín sobrepasó esta disposición (o, cuanto menos, exprimió el lenguaje de la ley) para habilitar a las FFAA a realizar este tipo de inteligencia. Lo fundó en las amenazas del "terrorismo subversivo" que atacaba a la Nación en su conjunto. Las FFAA, se dijo, necesitaban tener 
Esta revista forma parte del acervo de la Biblioteca Jurídica Virtual del Instituto de Investigaciones Jurídicas de la UNAM

herramientas para anticipar otro ataque como el sucedido en La Tablada y, para ello, debían realizar inteligencia interna. Nada hizo el Congreso para frenar estas avanzadas del PE.

\section{Carlos Menem}

Al año siguiente, el presidente de la nación ya era Carlos S. Menem, quien ofrece ejemplos aún más elocuentes de las victorias del $\mathrm{PE}$ en asuntos militares y de defensa nacional. En este caso, ya no es solo la intervención de las FFAA en cuestiones internas, sino la participación de éstas fuera de las fronteras nacionales y, además, la vinculación con actos de contrabando y corrupción.

Menem, al igual que Alfonsín, hizo intervenir a las FFAA para reprimir el tercer levantamiento Carapintada que se dio durante su presidencia en 1990. El 3 de diciembre de ese año, liderados por Mohamed Alí Seineldín (quien era reconocido por su participación en la Guerra de Malvinas), los Carapintada tomaron el Edificio Libertador (sede del Ministerio de Defensa) y otras dependencias. La orden de represión mediante las FFAA se emitió sin negociación previa. El saldo fue de trece muertos, cinco de ellos civiles (Larraquy, 2017: 710-711).

Al año siguiente se sancionó la ley 24054 de seguridad interior, promulgada en enero de 1992. Si esta ley puede entenderse como complemento de la de defensa nacional de 1988, hay autores que la consideran un paso atrás (Escolar, 2017: 37-39). La ley se sancionó con la sombra de La Tablada y de los levantamientos Carapintada. Por eso es que esta legislación consagró la posibilidad, como vimos, de que las FFAA actuaran en caso de declaración de estado de sitio, a la par que autorizó su empleo cuando se viera atacada una jurisdicción militar, más las funciones de apoyo logístico a las fuerzas de seguridad.

Sin embargo, esta crítica puede matizarse. La nueva ley mantiene e incluso profundiza la distinción entre seguridad interior y defensa nacional. El artículo 3 menciona a las fuerzas policiales y de seguridad como responsables de la seguridad interior, definida en el artículo anterior. El Congreso de la Nación seguía mostrando un consenso multipartidario al circunscribir las tareas de las FFAA a la defensa ante agresiones externas, reservando los asuntos internos a las fuerzas de seguridad. Aunque pue- 
Esta revista forma parte del acervo de la Biblioteca Jurídica Virtual del Instituto de Investigaciones Jurídicas de la UNAM

dan señalarse desaciertos, el PL siguió buscando regular la actuación del presidente.

No obstante, el PE continuó ganando frente al Congreso, ya no en asuntos internos, sino en el exterior. Esta es la novedad más importante del periodo.

La política internacional de Menem, como es sabido, se basó en el alineamiento automático con Estados Unidos (Rapoport, 2017: 163-169), lo cual impactó decididamente en asuntos militares. Fue durante su gobierno que Argentina se involucró decididamente con contingentes de las FFAA en misiones multinacionales o auspiciadas por Naciones Unidas (Simonoff, 2005; Diamint, 2014: 172-175) ${ }^{6}$. El impacto positivo o negativo en términos de política exterior, formación, experiencia militar y generación de capacidades de defensa merecería otro tipo de análisis. Desde una perspectiva jurídica, es evidente que en estas misiones las FFAA realizan tareas propias de seguridad interior, es decir, actividades prohibidas en el interior de Argentina (Lafferreriere y Soprano, 2015: 168). Esto implica una disociación entre la misión dispuesta por la ley de defensa nacional y las tareas que llevan a cabo en base a una decisión de política internacional del presidente. Con diferencias, esto se mantuvo en las presidencias posteriores.

No obstante, el primer momento donde más claramente se vio que el PE vencía de manera inapelable al PL fue durante la Guerra del Golfo. Ante la decisión en favor del uso de la fuerza que tomó el Consejo de Seguridad de Naciones Unidas por la invasión de Irak a Kuwait, Argentina se unió a la Coalición liderada por Washington. Menem, sin pasar por el Congreso Nacional, decretó el envío de cuatro navíos de la Armada Nacional para llevar adelante tareas de bloqueo naval y escolta en el Golfo Pérsico.

El envío de una flota de guerra sin autorización del Congreso es una violación flagrante del reparto de competencias militares que indica la $\mathrm{CN}$. $\mathrm{La} \mathrm{CN}$ requiere de autorización del PL para la "salida de las fuerzas nacionales" del territorio de la Nación (actual artículo 75.28, en ese momento $67.25, \mathrm{CN})$. Sin embargo, el envío de la flota militar se hizo por el escueto decreto número 1871 del 19 de septiembre de 1990. Sólo el 13 de febrero de 1991, i.e. cuando la guerra estaba a poco más de diez días de concluir,

\footnotetext{
6 Agradezco la recomendación de uno de los evaluadores anónimos, quien sugirió resaltar las misiones humanitarias de las FFAA en el exterior, algo que no habíamos hecho en la primera versión.
} 
Esta revista forma parte del acervo de la Biblioteca Jurídica Virtual del Instituto de Investigaciones Jurídicas de la UNAM

se publicó en el boletín oficial la ley del Congreso que lacónicamente "autoriza al Poder Ejecutivo nacional para disponer medidas para que la fuerza argentina en el Golfo Pérsico preste el apoyo apropiado, no pudiendo realizar las acciones bélicas directas".

En ese momento, se argumentó que la autorización del Congreso no era requisito porque la flota argentina se enviaba con objetivos humanitarios y no bélicos. Que no haya realizado acciones bélicas es más que discutible. El destructor ARA Almirante Brown y la corbeta ARA Almirante Spiro, más sus relevos, la corbeta ARA Rosales y el buque ARA Bahía San Blas, estuvieron destinados al bloqueo marítimo en el golfo de Omán. Y el bloqueo es propiamente una acción militar. Pero esto puede considerarse irrelevante, ya que la $\mathrm{CN}$ no exige que la salida de tropas sea con fines de entrar en combate para que se requiera la autorización del Congreso de la Nación. La violación a la CN es clara y el PE ganó, no solo porque logró hacer salir a la flota sin autorización del Congreso, sino también porque éste lo acompañó con posterioridad y, de alguna manera, saneó lo que había sido un avasallamiento en sus facultades.

La segunda victoria del PE constituyó uno de los episodios más bochornosos del periodo menemista en cuestiones militares y que más parecido tiene con el escándalo Irán-Contra norteamericano: el de la venta de armas a Ecuador y Croacia entre 1991 y 1995. La trama de hechos no ha sido dilucidada completamente y los procesos judiciales llegaron a puntos muertos durante más de dos décadas. Los principales acusados fueron absueltos en 2011 y en 2018 se cerró la causa.

Los acusados -entre ellos los ex ministros de Defensa Oscar Camilión y Erman González, el ex canciller Guido Di Tella, el propio ex presidente Carlos Menem, entre otros- habrían participado en la venta de toneladas de armamentos a Ecuador, en el contexto de su guerra contra Perú, y a Croacia durante el conflicto por la desintegración de Yugoslavia. En ambos casos, la operación fue secreta (Santoro, 2013, 8 de marzo); en los dos conflictos, Argentina se había comprometido públicamente a ser mediador (caso Ecuador) o neutral y hacer cumplir el embargo de armas con todos los beligerantes (caso Croacia) (Piñeiro, 2013).

Los avatares judiciales no son abordados aquí, ya que la relación entre el PE y el Judicial quedará para otro trabajo. Sin embargo, debe notarse que el Congreso no solo fue impotente ante el contrabando que impulsó el PE, 
Esta revista forma parte del acervo de la Biblioteca Jurídica Virtual del Instituto de Investigaciones Jurídicas de la UNAM

sino que fue deferente con él cuando se quiso realizar una investigación que no llegó a ninguna conclusión.

En marzo de 1995, se interpeló al ministro de defensa Oscar Camilión para que diera explicaciones en la Cámara de Senadores de la Nación. Allí fue acusado por bloques opositores e incluso por la, en ese momento, senadora Cristina Fernández de Kirchner, quien integraba el bloque del Partido Justicialista (oficialismo) y pidió su renuncia (Jastreblansky, 2011, 5 de septiembre). Recién en julio del año siguiente Camilión renunciaría, por lo que no habría una relación de causalidad entre la interpelación del Congreso y su alejamiento del cargo. Las crónicas de esos años enlazan la dimisión con el proceso judicial por la venta de armas y no por la actuación del Congreso (La Nación, 1996, 17 de julio). Posiblemente también se debió al nivel del escándalo, que fue tanto interno como internacional. Sobre todo en el caso croata, Argentina estaba formando parte del conflicto que se disputaba entre Occidente, que apoyaba a Croacia y BosniaHerzegovina, y Rusia, que se inclinaba por Serbia, por lo que su accionar se conoció fronteras afuera del país.

Lo que es indudable es que la participación del PL no fue más allá de esa interpelación. No se creó una comisión de Investigación, que es una facultad implícita (artículo 75.32 CN) del Congreso según la práctica y la doctrina constitucional. No hubo juicio político a los ministros (que pueden ser acusados por la Cámara de Diputados y destituidos por la de Senadores, artículo 53 y $59 \mathrm{CN}$ ) ni, por supuesto, del presidente.

El Congreso ni siquiera modificó la legislación reclamando una intervención en el proceso de exportación de armas. Según el artículo 34 de la Ley 12.079, la exportación es una facultad que tiene el PE. Sin embargo, el texto original de la ley, que data de 1941, establecía que superado cierto valor (que habría que actualizar) se requería autorización del Congreso. Esta autorización fue derogada por la ley 20010 de 1972 (gobierno de facto). Desde ese momento, la obligación del PE es, simplemente, "dar cuenta" de la operación al Congreso. Reasumir esta facultad parecía la primera acción frente a un escándalo semejante, pero no se hizo. Algo similar sucedió en Estados Unidos con los intentos frustrados del Congreso de frenar la venta de armas de Nixon y la ausencia de iniciativa luego del escándalo Irán-Contra (Koh, 1990: 49-52).

De hecho, el senador Alberto Maglietti presentó un proyecto de ley el 2 de junio de 1998 para establecer que el Senado debía aprobar las ventas 
Esta revista forma parte del acervo de la Biblioteca Jurídica Virtual del Instituto de Investigaciones Jurídicas de la UNAM

de armas al exterior. El proyecto era sin dudas defectuoso. En cualquier caso, no fue tratado y caducó ${ }^{7}$. No obstante, uno más elaborado en 2006, propuso el establecimiento de un "Código de Conducta de Exportaciones de Armas, Material Bélico, Tecnologías y Bienes de Uso Dual”, presentado por los legisladores Mario Domingo Daniele y María Cristina Perceval, tuvo el mismo destino que el de Maglietti. ${ }^{8}$ En definitiva, el Congreso no hizo demasiado ni para investigar ni para intentar remediar la situación.

Menem finalizó su mandato invicto frente al Congreso: las FFAA se involucraron de lleno en tareas de seguridad en el exterior del país, envió una flota de guerra sin autorización del PL, hizo intervenir a las FFAA en asuntos internos para reprimir un alzamiento militar y montó una operación secreta de venta de armas a dos países en guerra.

\section{De los Kirchner a Mauricio Macri}

El PE pareció ponerse de acuerdo con el Congreso mediante el decreto 727/06 del presidente Kirchner. El PE, quizás de forma inédita en la historia nacional, auto restringió sus potestades sobre las FFAA. Lo hizo mediante la decisión de acotar el margen de actuación del Ejército, la Marina y la Fuerza Aérea a agresiones que provengan de fuerzas armadas de otro Estado. De este modo, como afirma la fundamentación del decreto, se evitaba la consideración del terrorismo o el narcotráfico como amenazas que las FFAA deban combatir, tal como se promovía a partir de la war on terror desde Estados Unidos. ${ }^{9}$

Esta restricción presidencial autoimpuesta se mantuvo en líneas generales, pero también se violentó. No se hizo mediante acciones espectaculares ni operaciones que hayan comprometido seriamente derechos individuales, a diferencia de los periodos anteriores. Sin embargo, la presidenta Cristina Fernández de Kirchner (sucesora de su marido) decidió, a instancias de sus ministros de defensa y de seguridad, que centenares de efectivos militares fueran afectados a tareas de patrullaje aéreo e incluso terrestre en la región noroeste y noreste del país.

\footnotetext{
7 http://www.senado.gov.ar $/$ web/proyectos/verExpe.php?origen $=$ S\&tipo $=P L \&$ nume $x p=891 / 98 \&$ nro_comision $=\& t$ Consulta $=3$.

8 http://www.senado.gov.ar/web/proyectos/verExpe.php?origen $=S \&$ numexp $=1055 /$ $06 \&$ tipo $=P L \& t$ Consulta $=1$.

9 Hemos tratado esta problemática en Tripolone (2018a).

Cuestiones Constitucionales, Núm. 44, Enero-Junio 2021

ISSN: $2448-4881$
} 
Esta revista forma parte del acervo de la Biblioteca Jurídica Virtual del Instituto de Investigaciones Jurídicas de la UNAM

Según Marcelo Sain (2018), el quiebre se dio en 2013. Fernández de Kirchner inició un proceso de intervención menguada y solapada de las FFAA mediante el llamado Operativo Escudo Norte y Operativo Fortín II que tenían como objetivos el control del narcotráfico en la frontera norte del país (Sain, 2018: 89-197). Según el autor, el promotor de este plan fue el entonces jefe del Ejército César Milani. De ser cierto, habría aquí un retorno a la elaboración de la política de defensa desde las FFAA (y no desde el PE), algo que a partir de 2005 había cambiado. ${ }^{10}$

Esta mutación por parte del PE del rol de las FFAA que el Congreso había consagrado en la legislación fue, como se dijo, solapada y sin un discurso altisonante y militarista. Al contrario, con la asunción a la presidencia de Mauricio Macri, la orientación incluso discursiva cambió y se decidió por un rumbo contrario a la legislación, tanto en su letra como en su espíritu.

En general, la política de defensa de Macri modificó ciertos aspectos de la del kirchnerismo. Macri buscó darle mayor visibilidad a las FFAA (Calderón, 2017: 18-28), aunque solo un estudio más detallado posibilitaría afirmar que esto implicó mayores márgenes de autonomía en la toma de decisiones. De cualquier modo, lo central está en cómo el presidente logró, sin necesidad de pasar por el Congreso de la Nación, profundizar un viraje hacia el involucramiento de las FFAA en tareas de seguridad sin que el Congreso pudiera evitarlo.

El cambio de rumbó se expresó legalmente con el decreto 683/18 que reformó el 727/06 del presidente Kirchner. Macri se valió de las facultades reglamentarias que la $\mathrm{CN}$ le otorga al presidente para eliminar la restricción del uso de las FFAA a ataques exteriores perpetrados por fuerzas armadas de otro Estado (artículo $1 \mathrm{dec}$. 727/06). Fundado expresamente en la idea de que el terrorismo o el narcotráfico pueden configurar "agresiones externas" en los términos de la ley de defensa nacional, el presidente ha habilitado a que sean utilizadas en este contexto $^{11}$.

Además, acentuó el rol de las FFAA en labores secundarias. El propio presidente enfatizó en su discurso que anticipaba el decreto, que las FFAA debían colaborar de forma más intensa en asuntos de seguridad (Casa Ro-

10 Véase lo afirmado en el apartado IV de este trabajo.

11 Hemos analizado este punto en Tripolone (2018b). Aunque excede los límites temporales de nuestro trabajo, la disposición de Macri fue derogada por el decreto 571/2020 de Alberto Fernández el 26 de junio del 2020. 
Esta revista forma parte del acervo de la Biblioteca Jurídica Virtual del Instituto de Investigaciones Jurídicas de la UNAM

sada, 2018, 23 de julio). Esto, que violenta el espíritu de la ley de defensa nacional y la legislación de seguridad interior (por las mismas razones que lo hace el involucramiento de las FFAA en el Operativo Escudo Norte), no ha podido ser detenido por el Congreso Nacional.

Lo mismo sucede con la evidente inconstitucionalidad de una de las disposiciones del decreto 683/18. Como hemos señalado en otro trabajo (Tripolone, 2018a), la ley de defensa nacional reserva a la Gendarmería Nacional y Prefectura Naval la custodia de los llamados "objetivos estratégicos" del artículo 31 de dicha ley. El presidente Macri decretó que estos objetivos iban a ser custodiados por efectivos de las FFAA, lo cual no es simplemente un exceso reglamentario, sino una clara violación a la ley del Congreso. Sin embargo, la aquiescencia del PL (más la ausencia de causas judiciales que permitan a los tribunales actuar) hacen que el presidente triunfe en su iniciativa.

\section{Intermedio}

Hay diferencias en todos los casos reseñados. El de la Guerra del Golfo y la venta de armas a Ecuador y Croacia son asuntos internacionales, siendo todas las demás cuestiones internas. A su vez, la venta de armas fue una decisión secreta y atravesada por un caso de corrupción bochornosa. El resto pueden ser decisiones políticas negativas e ilegales, pero no involucran causas por corrupción.

El caso de La Tablada constituye un ejemplo de conflicto armado interno, más allá de que haya durado menos de dos días completos. Así fue calificado por la Comisión Interamericana de Derechos Humanos cuando se llevó el caso a su jurisdicción. Durante la represión en La Tablada se presume que se cometieron violaciones a los derechos humanos y, según la Comisión, posiblemente al derecho internacional humanitario. ${ }^{12}$

El involucramiento de las FFAA en el Operativo Escudo Norte y Fortín II sería el más "inofensivo" desde el punto de vista de las violaciones a las garantías individuales y las libertades. Sin embargo, se hizo justo en el contexto en que el consenso parecía más consolidado y que el discurso del propio gobierno parecía fomentar. Esto reafirma la tesis de este artículo:

12 Sobre el problema de la aplicación del derecho internacional humanitario por los órganos interamericanos, con referencias a La Tablada, véase Buis (2008).

Cuestiones Constitucionales, Núm. 44, Enero-Junio 2021

ISSN: $2448-4881$ 
Esta revista forma parte del acervo de la Biblioteca Jurídica Virtual del Instituto de Investigaciones Jurídicas de la UNAM

incluso con las leyes vigentes de separación entre defensa y seguridad sostenidas por un consenso generalizado dentro de la elite dirigente y la ciudadanía, el PE puede vulnerar los márgenes legales en el uso de las FFAA sin que tenga resistencia. El caso de Macri es similar, solo que vinculó la inserción de las FFAA en tareas de seguridad como una política militar positiva, a diferencia de lo que se promovía -en líneas generales- en los años de Cristina Fernández.

Sea como fuere, en todos estos casos que hemos repasado, el PE ha logrado imponer su supremacía sobre el PL en cuestiones militares y de defensa nacional e incluso vulnerar la legislación del Congreso y la propia $\mathrm{CN}$.

\section{LAS RAZONES DE LAS VICTORIAS}

\section{Razones constitucionales}

La cláusula de comandante en jefe y la facultad de disposición de las FFAA según las necesidades de la Nación, como se vio, son preceptos constitucionales vagos que permiten al presidente adjudicarse amplias potestades para valerse del instrumento militar. Esto se amplía aún más con interpretaciones de la $\mathrm{CN}$ como las que vimos realizan Bidart Campos (1999), Sinópoli (2003) o Palazzo (2010), quienes sostienen que son inconstitucionales las pretensiones de controlar la facultad presidencial de disponer de las FFAA.

Además, el presidente puede declarar el estado de sitio por sí mismo en el caso en que el Congreso esté en receso. En este supuesto, la ley de seguridad interior habilita la utilización de las FFAA para restablecer el orden interno. Incluso en el supuesto en que el Congreso, una vez reunido, rechace el estado de sitio, el presidente podría valerse de las FFAA desde su declaración hasta ese momento. La dificultad y los tiempos necesarios para reunir al Congreso fuera de las sesiones ordinarias posibilitan la utilización de las FFAA por el PE durante un lapso prolongado. Además, debe tenerse en cuenta las lealtades partidarias de los legisladores para con el presidente, más los costos políticos de rechazar un estado de sitio si la situación aparenta ser una emergencia real. 
Esta revista forma parte del acervo de la Biblioteca Jurídica Virtual del Instituto de Investigaciones Jurídicas de la UNAM

\section{Razones de mando de las FFAA}

Las FFAA necesitan de un mando único y centralizado, eso es algo claro y difícil de discutir. El Congreso no tiene las características que tiene el PE de unidad, celeridad y secreto que son imprescindibles cuando debe afrontarse una amenaza militar, más allá de que pueden resultar problemáticas en contextos de normalidad (sobre todo el secreto cuando no es imprescindible y la celeridad si se entiende como actuación sin debate previo). Por tanto, es lógico que en todo lo relativo a las FFAA la balanza se incline hacia el PE.

Sin embargo, tal como sostiene Baker (2007: 26) para el caso de Estados Unidos, el mando de quien ejerce la presidencia no debería ir en desmedro de un control posterior del Congreso y el Poder Judicial. Es obvio que este control tiende a proteger garantías individuales, pero también protege la política de defensa en general. Ese control legitima el accionar de las instituciones militares frente a un público normalmente reacio a su actuación y muy sensible frente a abusos de poder (Baker, 2007: 27).

\section{Razones históricas}

El Congreso de la Nación no ha sido activo en materia de defensa y asuntos militares. Esto se debe en buena parte a la desatención del PL, pero también a lo visto en el punto anterior: el centro de la escena está en el PE, el cual expande su poder aún más en situaciones de emergencia. Como vimos, el Congreso Nacional ha tendido a refrendar la lucha del PE por dominar a las FFAA, pero no intentar controlar al presidente si excede los marcos legales.

Si se toman los dos periodos más importantes de reformas en cuestiones militares se aprecia esta lógica. El primer periodo es el de las últimas dos décadas del siglo XIX. En él se logró el sometimiento de las milicias y las Guardias Nacionales que, aunque representaban el ideal republicano del ciudadano-soldado y la defensa de la patria por todos los hombres del país, constituían factores de poder provincial que enervaban la autoridad del Estado nacional (Macías y Sabato, 2013: 70-81). A partir de 1880 comenzó la centralización de las FFAA y con ello el poder armado se aglutinó en el Estado Nacional. Esto se consolidó con la ley Riccheri en 1901, pero tuvo 
Esta revista forma parte del acervo de la Biblioteca Jurídica Virtual del Instituto de Investigaciones Jurídicas de la UNAM

su origen en las pugnas del PE nacional a partir de 1880 con los poderes provinciales.

El segundo periodo está constituido por las últimas dos décadas del siglo XX que, como vimos en este artículo, estuvieron signadas por el sometimiento de unas FFAA que habían adquirido amplios márgenes de autonomía y sentido corporativo (Montenegro, 2013). Como dijimos más arriba, el rol del Congreso fue aquí mucho más evidente e importante con la sanción de las leyes de defensa nacional y seguridad interior. Sin embargo, esta legislación fue el resultado también del esfuerzo del PE que comenzó en 1983 por hacer valer su autoridad sobre las FFAA y no por iniciativa propia del PL. De hecho, el proyecto ingresó al Congreso en 1985 y demoró tres años en sancionarse.

En ambos casos, cuando el PE vulneró la legislación del Congreso, éste no utilizó sus herramientas de control para encarrilar la conducta del presidente en los marcos legales. Aún más, el PL refrendó lo actuado por el PE, como sucedió en el caso del envío de la flota de guerra al Golfo Pérsico.

\section{Razones de formación política}

Los partidos políticos tampoco han sabido estar a la altura de lo que requiere la política de defensa. Esto lo señala en su ya clásico estudio Ernesto López (1994), quien muestra cómo el Partido Justicialista y la Unión Cívica Radical fueron ambiguos en materia militar durante la transición democrática. El primero se opuso a la anulación de la ley de autoamnistía y fue por demás oscilante frente a los juicios a las juntas militares. Algunos de sus miembros se manifestaron en contra de la ley de defensa de 1988, más allá del acuerdo final. Por otro lado, la UCR pregonaba juzgamiento por los crímenes de la dictadura militar, pero apoyó las leyes de punto final y obediencia debida y la limitación de los procesos a los altos mandos.

En general, existe una desatención de la clase política en los temas de defensa. Nadie gana elecciones con propuestas sobre defensa nacional y, por tanto, jamás figura en las prioridades de campañas electorales o de la agenda pública. Esta desatención también puede deberse a la marginación del país y la región de la agenda global y el escaso poder político de Argentina para incidir en cuestiones de seguridad internacional, tanto en la toma de decisiones como en la efectiva participación militar (Diamint, 2014: 
Esta revista forma parte del acervo de la Biblioteca Jurídica Virtual del Instituto de Investigaciones Jurídicas de la UNAM

27-29, 37 y 443). A esto se le suma que los estudios sobre defensa nacional en la academia argentina siguen siendo escasos (Diamint, 2014: 45-48; Lafferriere y Soprano, 2015: 13-15), por lo que la elite política no encuentra personal civil capacitado para ocupar puestos importantes en el Ministerio de Defensa o de legisladores o asesores en el Congreso Nacional.

Esta falta de preparación sobre asuntos de defensa y temas militares de los partidos políticos, los dirigentes y la academia reproducen el esquema que presenta Montenegro (2013): la toma de las decisiones principales y la formulación de políticas en el área son delegadas en las FFAA. En definitiva, el PL se ve sobrepasado por el PE quien, a su vez, delega parte de las decisiones en las instituciones castrenses. Éstas se educan a sí mismas (porque faltan académicos civiles) y se gestionan sus propios planes operacionales.

\section{Razones contextuales a nivel mundial}

Argentina no es una anomalía. La concentración de facultades en el PE es algo que se replica en otros países, sobre todo en el continente americano que cuenta con sistemas presidencialistas. Pero no solo allí. En cualquier lugar donde se den situaciones de emergencias, tal como sostiene Ignatieff (2005: 110), el público suele requerir acciones rápidas y eficaces para acabar con la amenaza dejando al PE "cada vez con menos ataduras - porque ya no teme el examen ni el control eficaz por parte de la Asamblea Legislativa o de las Cortes - y cree que puede "dejarse de contemplaciones' y actuar con impunidad" con tal de salvar al Estado.

Este contexto mundial de emergencia permanente ayuda a que la fuerza centrípeta del ejecutivo aglutine cada vez más poder en su órbita. Tanto que autores como Posner y Vermeule (2011) hablan de un Executive unbound, es decir, un poder ejecutivo sin límites legales. Para los autores, la ley está impedida de controlar al ejecutivo en una situación global donde sus poderes se expanden, sobre todo ante emergencias. Los únicos controles provienen de la opinión pública y las relaciones de fuerza políticas (Posner y Vermeule, 2011: 1-17). Como decía Madison, a quien Yoo (2009: 28) cita para sostener su posición sumamente favorable al ejecutivo, "las medidas de seguridad solo pueden regularse por los medios y el peligro del ataque". Con lo cual, se está a merced de lo que la sociedad y la elite dirigente haga al respecto $\mathrm{y}$, como dijimos, el involucramiento de 
Esta revista forma parte del acervo de la Biblioteca Jurídica Virtual del Instituto de Investigaciones Jurídicas de la UNAM

estos sectores en asuntos militares y de defensa es escaso y con escasa formación.

\section{CONCLUSIÓN: DE LA IMPOTENCIA A UNA PROPUESTA REALISTA}

La hipótesis de este trabajo, inspirada en el estudio de Harlod Koh (1990) en Estados Unidos, de una primacía del PE y una deferencia del PL en asuntos militares y de defensa nacional está ampliamente comprobada. El problema no es tanto la primacía, que no sería reprochable o grave en sí mismo en la medida en que surja de la $\mathrm{CN}$. El punto central es que existe una tolerancia a las violaciones de la voluntad expresa del Congreso manifestada en la legislación. Aún más, pueden encontrarse casos en que se han ignorado preceptos constitucionales claros.

En asuntos militares, los controles del Congreso frente al poder presidencial parecen impotentes. De ser cierto, se probaría, para Argentina, lo que Koh (1990), Yoo (2006 y 2009), Posner y Vermeule (2007 y 2011), entre otros, afirman para Estados Unidos. Esto es así más allá de la abrumadora diferencia que existe entre ambos países en este tema. Las decisiones que toma la Casa Blanca contraviniendo los controles internos de su Estado han provocado guerras con consecuencias devastadoras alrededor del mundo. En Argentina, los efectos son sobre todo locales y, al menos en las últimas décadas, las consecuencias han sido graves, pero ni remotamente cercano a lo sucedido en Vietnam o Irak.

Sin embargo, más allá de esto, lo importante es estar alerta frente a una realidad que debe tenerse en cuenta: el PE, si se lo propone, parece poder vulnerar los marcos legales e incluso constitucionales. Hasta ahora, la historia constitucional muestra que el Congreso no ha podido detenerlo. Aunque no ha sido objeto de análisis aquí y queda para trabajos posteriores, el Poder Judicial tampoco.

Esta comprobación no nos debería hacer pensar, como dijimos en la introducción, en un estado de inocencia y legalidad pura que se perdió en algún punto de la historia nacional. Siempre el PE ha primado sobre el PL en esta materia. Tampoco nos debería hacer creer que la solución está en reducir al mínimo las facultades presidenciales mediante más leyes. Es clarísimo que una legislación que promueva las consultas entre el PE y el PL (o, al menos, con las comisiones del Congreso encargadas del tema) sería positiva. Pero si este trabajo prueba algo es justamente la impotencia 
Esta revista forma parte del acervo de la Biblioteca Jurídica Virtual del Instituto de Investigaciones Jurídicas de la UNAM

de esta legislación para frenar el poder presidencial si éste se propone avanzar sobre ella. Además, si por hipótesis pudiese lograrse, en situaciones de emergencia real, la historia demuestra que el público exige medidas presidenciales eficaces y rápidas, que no podrían tomarse si la limitación fuera real, por lo que las consecuencias serían desastrosas.

¿Cómo pueden, entonces, evitarse las violaciones a la legalidad y a la $\mathrm{CN}$ en asuntos de defensa nacional? La clave está en algo que la teoría jurídica (y también política) ha olvidado y que es fundamental: la preparación y formación del político, en este caso, en asuntos de defensa nacional.

La formación política de la clase dirigente ha sido tradicionalmente relegada (Ghiretti, 2014: 325-347). Una dirigencia política poco formada puede pensar que la solución para asuntos como el narcotráfico o las (muy menores) amenazas terroristas está en el involucramiento de las FFAA. Aunque el Congreso no quiera modificar la legislación, el único escollo ante la voluntad de superarla lo tendrá en la opinión pública. Sin embargo, ésta puede cambiar. Acicateada por la idea de una emergencia o incluso ante un reclamo social genuino, una dirigencia sin formación (ni escrúpulos) no tendrá el límite de la ciudadanía para imponerse sobre un Congreso que se muestra impotente en la materia.

Por tanto, se necesitan dirigentes a la altura del desafío. Y no sólo con formación intelectual, sino también éticamente aptos. Como señala Baker (2007) específicamente para ámbitos de la defensa nacional, estamos a merced de seres humanos (y no de leyes) mucho más de lo que quisiéramos admitir. Ante la imposibilidad de controlar el secreto, la rapidez y la unidad de mando del ejecutivo en asuntos de defensa nacional, ésta se vuelve una de las áreas del gobierno que más depende de la integridad moral de quienes ocupan puestos públicos (Baker, 2007: 11).

Formación intelectual e integridad moral son la base que informa la virtud central del político, esto es, la prudencia. Estas consideraciones son ajenas a las que usualmente se hacen desde la ciencia jurídica, siempre propensa a buscar soluciones a todos los problemas políticos y déficits del sistema en normas generales. Sin embargo, la letra de una nueva ley, al menos en el ámbito de la defensa nacional y los poderes militares, es siempre factible de ser sobrepasada por los poderes del PE. Como afirma Palacio (1973: 55) más en general, "la menor o mayor suma del poder no depende del sistema que se practique o se proclame, sino de la persona que lo ejerza y sus dotes de inteligencia y voluntad". 
Esta revista forma parte del acervo de la Biblioteca Jurídica Virtual del Instituto de Investigaciones Jurídicas de la UNAM

Si esto es cierto, la clave está en volver la mirada hacia las personas que ejercen el poder. Esto no significa, en lo absoluto, ignorar la ley. Implica entender cómo se ejerce realmente el poder, al menos en este particular campo que es la defensa nacional. Incluso Aristóteles, que sostenía la necesidad de que no mande un hombre "sino la razón, porque el hombre manda en interés propio y se convierte en tirano" (Aristóteles, 2007: 113 [1134a]), entendía que el gobierno pasa, en definitiva, por los hombres. "Por más que Aristóteles sitúe en la cumbre de su teoría política a la ley, aparece por encima la figura semioculta del hombre de gobierno, que es el que le da, en última instancia, su fuerza coactiva" (Ghiretti, 2011: 111).

La ley otorga marcos de actuación que permiten anticipar las decisiones, pero solo en el supuesto en que exista voluntad y sabiduría por parte del gobernante para cumplirlas. La ley, como también pensaba Aristóteles, permite educar a los magistrados (Aristóteles, 2007: 142 [1287a]). Sin embargo, no puede sustituir la prudencia necesaria del gobernante, que debe tomar las decisiones que están fuera del alcance de la ley (Aristóteles, 2007: 139 [1286a]). La ciencia jurídica debe hacerse cargo también de aquellas áreas en donde, al menos hasta ahora, la arquitectura jurídicoconstitucional se revela incapaz de poner freno al poder. La defensa nacional es una de ellas.

\section{FUENTES CONSULTADAS}

ARISTÓTELES (2007). Ética Nicomáque (trad. de Julio Pallí Bonet y Tomás Calvo Martínez). Madrid: Gredos.

BAKER, J.E. (2007). In the common defense. National Security Law for perilous times. Cambridge: Cambridge University Press.

Bergen, P. L., The longest war. The enduring conflict between America and Al-Qaeda. Nueva York: Free Press.

Bidart CAMPOS, G. (1999). Manual de la Constitución reformada. Buenos Aires: Ediar.

Boot, M. (2003, 19 de febrero). "America's destiny is to police the world", Financial Times. Disponible: http://www.pennsylvaniacrier. com/filemgmt_data/files/Americas\%20Destiny\%20Is\%20to\%20Police\%20the\%20World.pdf. 
Esta revista forma parte del acervo de la Biblioteca Jurídica Virtual del Instituto de Investigaciones Jurídicas de la UNAM

BuIS, E. (2008). The implementation of International Humanitarian Law by Human Rights Courts: the example of the Inter-American Human Rights System. En R. Arnold y N. Qénivet (ed.), International Humanitarian Law and Human Rights Law: towards new merger in International Law (pp. 269-293). Leiden y Boston: Martinus Nijhoff Publishers.

Calderón, E. (2017). El perfil doméstico de la política de defensa macrista: más continuidades que cambios. Algunas notas sobre su impacto en términos de inserción. Cuadernos de política exterior argentina 125 , pp. 18-28.

Casa Rosada (2018, 23 de julio). El presidente Mauricio Macri anunció la reforma del Sistema de Defensa Nacional. disponible: $h t t p s: / / w w w$. casarosada.gob.ar/informacion/discursos/43216-el-presidente-mauricio-macri-anuncio-la-reforma-del-sistema-de-defensa-nacional.

Comisión Interamericana de Derechos Humanos (1997, 18 de noviembre). Informe $\mathrm{N}^{\circ}$ 55/97, caso 11.137, Juan Carlos Abella Argentina.

DerGhogassian, K. (2012). Evolución de la política de defensa. En K. DerGhougassian (comp.), La defensa en el siglo XXI. Argentina y la seguridad regional (pp. 13-46) Buenos Aires: Capital Intelectual.

DerGhogassian, K. (2010). Prólogo. En N. Garré (ed.), Colección debates parlamentarios de la defensa: ley de defensa nacional. Buenos Aires: Ministerio de Defensa.

Diamint, R. (2014). Sin gloria. La politica de defensa en la Argentina democrática. Buenos Aires: Eudeba.

Ekmekdjin, M. Á. (1997). Tratado de derecho constitucional. Tomo I. Buenos Aires: Depalma.

Ekmekdjian, M. Á. (1994). Tratado de derecho constitucional. Tomo II. Buenos Aries: Depalma.

ESCOLAR, D. (2017). Gendarmería. Los límites de la obediencia. Buenos Aires: SB editorial.

FERnÁndez Rodríguez, J. J. y SANSÓ-RuPERT, P. D. (2010). El recurso constitucional a las fuerzas armadas para el mantenimiento de la seguridad interior: el caso de Iberoamérica. Boletín Mexicano de Derecho Comparado XLIII (128). Disponible: https://revistas.juridicas.unam. mx/index.php/derecho-comparado/article/view/4625. 
Esta revista forma parte del acervo de la Biblioteca Jurídica Virtual del Instituto de Investigaciones Jurídicas de la UNAM

GHIRETTI, H. (2014). La madurez del político. La relación entre juventud y responsabilidad de gobierno. En: AAVV, Escribir en las almas. Estudios en honor a Rafael Alvira (pp. 325-347). Pamplona: EUNSA.

GHIRETTI, H. (2013). Una presencia revelada. El gobernante en la filosofía práctica aristotélica. En R. Lázaro Cantero (ed.), De ética y política. Conceptos, historia, instituciones (pp. 103-146). Madrid: Tecnos.

Huntington, S. (2002). The soldier and the State. Theory and politics of civil-military relations. Cambridge: Harvard University Press.

IGNATIEFF, M. (2005). El mal menor. Ética politica en una era de terror (trad. María José Delgado), Madrid: Taurus.

JASTREBLANSKY, M. (2011, 5 de septiembre). Cristina legisladora: 10 recuerdos de una opositora mediática y rebelde. La Nación. Disponible: https://www.lanacion.com.ar/1403365-cristina-legisladora-10-recuerdos-de-una-opositora-mediatica-y-rebelde.

KANT, I. (2010). Hacia la paz perpetua (trad. Maximiliano Hernández). Madrid: Gredos.

KoH, H. (1990). The National Security Constitution. Sharing power after Iran-Contra affair. Londres y New Haven: Yale University Press.

LAFFERriere, G. y Soprano, G. (2015) El Ejército y la política de defensa en la Argentina del siglo XXI. Rosario: Prohistoria.

LARRAQUY, M. (2017). Argentina. Un siglo de violencia política, 18901990: de Roca a Menem. La historia de un país. Buenos Aries: Sudamericana.

LÓPEZ, E. (1995). Ni la ceniza ni la gloria. Actores, sistema político y cuestión militar en los años de Alfonsín. Buenos Aires: Universidad Nacional de Quilmes.

MAcíAS, F. y SABATO, H. (2013). La Guardia Nacional: Estado, política y uso de la fuerza en la Argentina de la segunda mitad del siglo XIXPolHis 6 (11), pp. 70-81. Disponible: http://historiapolitica.com/datos/ boletin/Polhis11_MACIASSABATO.pdf.

Montenegro, G. (2013). Más vale pájaro en mano que cien volando. La implementación del control político civil sobre las Fuerzas Armadas. La experiencia argentina 2005-2010. Entre la voluntad política y las limitaciones prácticas. En D. Pion-Berlin y J.M. Ugarte (coord.), Organización de la defensa nacional y control civil de las fuerzas ar- 
Esta revista forma parte del acervo de la Biblioteca Jurídica Virtual del Instituto de Investigaciones Jurídicas de la UNAM

madas en América Latina (pp. 196-199). Buenos Aires: Jorge Baudino Ediciones.

Palacio, E. (1973). Teoría del Estado. Buenos Aires: Eudeba.

Palazzo, E. (2010). Competencias del Congreso en materia de defensa nacional. En D. Sabsay (dir.) y P.L. Manili (coord.), Constitución de la Nación Argentina y normas complementarias. Análisis doctrinal y jurisprudencial. Volumen 3 (pp. 816-840). Buenos Aires: Hammurabi.

PiÑEIRO, L. (2013). Lo que Croacia se llevó de la Argentina. Defensa.info. Disponible: https://www.defensa.com/reportajes/que-croacia-se-llevoargentina.

Posner, R. y Vermeule, A. (2007). Terror in balance. Security, liberty and the courts. Nueva York: Oxford University Press.

Posner, R. y Vermeule, A. (2011). The Executive unbound. After the Madisonian Republic. Nueva York: Oxford University Press.

Quiroga Lavié, H., Benedetti, M.Á. y Cenicacelaya, M.N. (2009). Derecho constitucional argentino. Buenos Aries: Rubinzal-Culzoni.

RApOport, M. (2017). Politica internacional argentina. Desde la formación nacional hasta nuestros días. Buenos Aires: Capital Intelectual.

SAIN, M.F. (2018). Las Fuerzas Armadas y la "guerra contra las drogas" en Argentina (2011-2018). En: J.G. ToKATLian, M.F. SAIN y G. MoNTENEGRO, De militares a policías. La "guerra contra las drogas" y la militarización de Argentina (pp. 89-197). Buenos Aires: Capital Intelectual.

SANTORO, D. (2013, 8 de marzo). Los vaivenes de la causa por la venta ilegal de armas a Ecuador y Croacia. Clarin. Disponible: https://www. clarin.com/politica/menem-causa_armas_0_Hk7SEI9jw7l.html.

SchmitT, C. (2005). Die Wendung zum diskriminierenden Kriegsbegriff. En C. SchMiTt, Frieden oder Pazifismus? Arbeiten zum Völkerrecht und zur internationalen Politik 1924-1978. Berlín: Duncker \& Humblot.

Simonof, A. C. (2005). Envíos de tropas y política exterior (1989-2005). Relaciones internacionales 28, pp. 127-159.

SinÓPOLI, S. M. (2003). El derecho constitucional militar. Tesis de doctorado. Buenos Aires: Universidad Católica Argentina.

Smith, J.E. (2016). Bush. Nueva York: Simon \& Shuster. 
Esta revista forma parte del acervo de la Biblioteca Jurídica Virtual del Instituto de Investigaciones Jurídicas de la UNAM

Starr-Deelen, D. G. (2014). Presidential policies on terrorism. From Ronald Reagan to Barack Obama. Nueva York: Palgrave Macmillan.

TRIPOLOnE, G. (2018a). Constitución y Fuerzas Armadas en el Siglo XXI. En Letra 5(10).

TRIPOLONE, G. (2018b). Nuevo panorama para las Fuerzas Armadas Argentinas. Ejércitos. Revista Digital sobre Armamento, Defensa y Fuerzas Armadas. Publicado el 19 de octubre de 2018.

UGARTE, J. M. (2013). Una visión desde Latinoamérica de la organización de la defensa y las relaciones civiles-militares. En PION-BERLIN, D. y UGARTE, J. M. (coords.), Organización de la defensa nacional y control civil de las fuerzas armadas en América Latina (pp. 53-98). Buenos Aires: Jorge Baudino Ediciones.

Yoo, J. (2006). War by other means. An insider's account of the war on terror, Nueva York: Atlantic Monthly Press.

Yoo, J. (2009). Crisis and Command. The history of Executive Power from George Washington to George W. Bush. Nueva York: Kaplan. 